\title{
ÉTICA Y CONTROL DE CONVENCIONALIDAD
}

\author{
ETHICS AND CONVENTIONALITY CONTROL
}

ÁLVARO MESA LATORRE*

\section{RESUMEN}

Este artículo, a partir de las nociones básicas de moral, ética, ética aplicada y ética judicial, explora si en la aplicación del control de convencionalidad -instituto jurisprudencial creado por la Corte Interamericana de Derechos Humanos para garantizar el goce y ejercicio de estos- la ética aplicada, la ética judicial, han desempeñado un rol protagónico. La materia ha sido muy poco estudiada por los autores. Ello, pues en la decisión final de un caso se analiza regularmente lo normativo, pero se omite el ámbito ético. Siendo este un aspecto esencial en la labor de los jueces.

Palabras clave: Control de convencionalidad, Decisión judicial, Ética judicial, Derechos humanos, Código moral básico, Orientación racionalmoral.

\section{ABSTRACT}

This article, based on the basic notions of moral, ethics, applied ethics and judicial ethics, explore if in the application of the control of conventionalityjurisprudential institute created by the Inter American Court of Human

\footnotetext{
* Licenciado en Ciencias Jurídicas, Universidad de Valparaíso. Abogado. Ministro de Ilma. Corte de Apelaciones de Temuco. Magíster en Derecho, mención Derecho Público, Universidad Católica de Temuco. Profesor Asociado Adjunto, de Teoría Política y Derecho Constitucional y Director del Centro de Estudios Constitucionales y Administrativos, Facultad de Humanidades, Escuela de Derecho, Universidad Mayor, sede Temuco, Chile. Correo: alvaromesalatorre@gmail.com. ORCID: https:// orcid.org/0000-0002-8578-3627.
}

Trabajo recibido el 15 de abril de 2021 y aceptado para su publicación el 15 de diciembre de 2021. 
Rights to guarantee the enjoyment and exercise of these - applied ethics, in this case, judicial ethics played a leading role. The topic has been little studied by the authors because in the final decision of a case it is often analyzed the normative side leaving the ethical side omitted. The last is an essential element in judges work.

Keywords: Basic moral code, Conventionality control, Judicial decision, Human rights, Judicial ethics, Moral-rational orientation.

\section{INTRODUCCIÓN}

La Ética, ${ }^{1}$ desde sus primeros constructos griegos ha sido la morada, el habitar que el ser humano ha buscado con insistencia, para alcanzar una vida armoniosa, digna de la condición humana propiamente tal, cualquiera sea la actividad o profesión que se realice. Ese habitar nos protege, transforma nuestras prácticas en valores humanos. Ese habitar, sensibiliza nuestro marco de acción. Ese habitar además, es uno de los mayores poderes de integración para los pensamientos y los recuerdos del hombre. ${ }^{2}$ Agregamos también para nuestras prácticas judiciales. Ese habitar, se ha ido constituyendo, ni más ni menos, en la delimitación de nuestro actuar.

Ética que, de inicio, podemos entender como aquel comportamiento que estamos en condiciones de aprobar. Ello significa que supone un estándar acerca del actuar correcto. ${ }^{3}$ ARISTÓTELES nos dirá que la virtud no es sólo un desafío individual sino una verdadera exigencia social y civilizadora. ${ }^{4}$

En esa ilación, la ética aplicada surge en respuesta a los problemas morales nuevos planteados al interior de las sociedades contemporáneas. ${ }^{5}$

\footnotetext{
${ }^{1}$ Cortina, Adela; Martínez, Emilio, Ética, Akal, Madrid, 2001, 3a edición, pp. 14-18. Siguiendo a los autores se utilizará la palabra Ética (mayúscula) para referirse a la Filosofía Moral y ética (minúscula) para referirse a las otras éticas. Ej.: ética kantiana.

${ }^{2}$ Bachelard, Gastón, La poética del espacio, Fondo de Cultura Económica, Buenos Aires, 2000, $4^{\text {a }}$ reimpr., $1^{\mathrm{a}}$ ed. argentina.

${ }^{3}$ Squella, Agustín, Introducción al Derecho, Editorial Jurídica de Chile, Santiago, 2001, p. 61.

${ }^{4}$ Alvear, Julio, "Algunas anotaciones sobre la enseñanza de la Ética jurídica", Actualidad Jurídica (Universidad del Desarrollo), 2002, año III, Nº 6, pp. 27-34.

${ }^{5}$ Escribar, Ana, "La ética aplicada, sus condiciones de posibilidad y las exigencias a las que responde", Revista de Filosofia, 2004, Vol. 60, pp. 19-28, http://repositorio.uchile.cl/bitstream/handle/2250/131966/
} 
En este caso la que practican los jueces, la denominada ética judicial. Ética judicial, en cuanto el deber ético del juez no es otra cosa que el cumplimiento, en grado de excelencia, de su deber jurídico. ${ }^{6}$

Todo lo precedente, lo enlazamos con la construcción jurisprudencial desarrollada por la Corte Interamericana de Derechos Humanos (Corte IDH), denominada control de convencionalidad (en adelante, control cv). Este control en la esfera internacional (fase externa) es la Corte IDH quien lo ejerce, realizando un examen de compatibilidad entre las normas del derecho interno y las normas de la Convención Americana Sobre Derechos Humanos (CADH) en aquellas causas que llegan a su conocimiento. Por otro lado en el ámbito interno el control $c v$ es realizado por los agentes del Estado al realizar el cotejo entre las normas internas con la $\mathrm{CADH}^{7}$ Ahora bien, la fase internacional o externa es la que se desarrolla en este artículo. En esa idea analizamos que en esta fase externa del control $c v$, la ética judicial, ha desempeñado y desempeña un rol significativo.

Para lograr lo indicado, el trabajo se desarrolla en las siguientes secciones: (II) Moral y Ética. La ética aplicada; (III) La ética judicial. Su aplicación; (IV) Control de convencionalidad; (V) Ética y control de convencionalidad; (VI) Jurisprudencia relevante sobre el control de convencionalidad de la Corte IDH. Finalmente (VII) las conclusiones, según propuesta.

\section{MORAL Y ÉTICA. LA ÉTICA APLICADA}

\section{El término moral}

El término moral tiene una multiplicidad de usos. ${ }^{8}$ Para nuestro estudio

\footnotetext{
La-etica-aplicada-suscondiciones-de-posibilidad-y-exigencias-a-las-que-responde.pdf?sequence, consultada: 10 de noviembre de 2018.

${ }^{6}$ Aguiló, Josep, “Dos concepciones de la ética judicial”, Revista DOXA, 2009, n 32, pp. 525-540, http:// www.cervantesvirtual.com/obra/dos-concepciones-de-la-etica-judicial/, consultada: 10 de octubre de 2018.

${ }^{7} \mathrm{NASH}$, Claudio, "Control de Convencionalidad en Chile. Bases normativas, Jurisprudencia y críticas", en: Henríquez, M.; Morales, M. (coords.) El Control de Convencionalidad: Un balance comparado a 10 años de Almonacid Arellano vs. Chile, DER Ediciones, Santiago de Chile, 2017, p. 404.

${ }^{8}$ Ferrater, José, Diccionario de Filosofía Abreviado, Editorial Sudamericana S.A., Buenos Aires, 2007,
} 
lo utilizaremos de dos formas, ello sin perjuicio de lo que se explicará en la Ética como Filosofía Moral: ${ }^{9}$ a) modelo de conducta socialmente establecido en una sociedad concreta. Alude a principios, patrones de conducta, valores, normas, ideales de vida buena, que forman un sistema más o menos coherente, propio de un grupo humano concreto en una época histórica determinada (la moral vigente); b) dimensión de la vida humana. A partir de la cual nos vemos obligados a tomar decisiones y dar razón de ellas (lo moral). Esta dimensión moral de la vida humana se refiere a la necesidad inevitable de tomar decisiones y llevar a cabo acciones a las que tenemos que responder ante nosotros mismos y ante los demás. Decisiones susceptibles de aceptación o rechazo como miembro de una comunidad. Es decir, afecta a la persona como un todo. ${ }^{10}$ Esto de inmediato -en relación al objetivo de nuestra propuesta- pues lo asociamos al trabajo que realizan los jueces de la Corte IDH, al aplicar el control cv (fase externa) y con ello la ética judicial, según se explicará con posterioridad.

\section{La moral y los derechos humanos}

En realidad, hay mecanismos donde somos capaces de entender que estamos hechos de una misma materia. Así, por ejemplo, la capacidad para la comunicación lingüística. Es un puente que nos da un símbolo de identidad. En ese orden de ideas, el derecho debe abrirse a la estructura de lo común, de lo jurídicamente común. ${ }^{11}$ Desde ese razonamiento, es posible indicar que con la expresión derechos humanos (DDHH), se alude a la común naturaleza jurídica que cualquier ser humano posee con independencia de cualquier otro atributo más local, más cultural, más histórico o más

$28^{\text {a }}$ edición, p. 248; Loewe, Daniel, Ética y Coronavirus, Fondo de Cultura Económica, Santiago, 2020, p. 57, quien expresa de una manera más general que el concepto de moral o sentido común lo constituye un repositorio de valoraciones, convicciones, juicios, principios e intuiciones.

${ }^{9}$ Cortina y Martínez, cit. (n. 1), pp. 14-18.

${ }^{10}$ Palacios, José, "Ética aplicada, interculturalidad y acción social", Revista del CISEN (Argentina), 2014, Vol. 2, n 1, pp. 63-83, http://ppct.caicyt.gov.ar/index.php/cisen/search/results, consultada: 1 de octubre de 2018; misma idea en BRAndT, Richard, Teoría Ética, Alianza Editorial, Madrid, 1994, pp. 432-436.

${ }^{11}$ López, José, "Prólogo", en: Angulo, G., Teoría contemporánea de los Derechos Humanos. Elementos para una reconstrucción sistémica, Editorial Dykinson, Madrid, 2015, pp. 1-21. 
parcial. ${ }^{12}$ Más preciso, los DDHH constituyen el nuevo derecho común del siglo XXI, el que contiene valores, principios y normas compartidos por la mayoría de los individuos. ${ }^{13}$ Por otro lado el tema de los DDHH hoy es un fenómeno social, político, jurídico, cultural y actúa como código elemental de una ética universalmente aceptada. La ética del respeto a la dignidad de la persona humana. ${ }^{14}$ Dignidad humana que es el principio supremo para la acción del Estado. ${ }^{15}$

\section{Una distinción necesaria}

Ahora bien, cabe precisar que la distinción jurídica entre DDHH y derechos fundamentales (DDFF) lo podemos realizar desde dos concepciones: a) parte importante del pensamiento jurídico europeo, entiende que los DDHH se consideran como elementos morales orientadores del deber ser del Estado. En cambio los DDFF son aquellos derechos que por su importancia política en un momento determinado encarnan el contenido de las leyes fundamentales de las constituciones de los Estados, como valores principales y normas específicas, provistos además de mecanismos concretos para su defensa y garantía; ${ }^{16}$ b) una parte destacable de las escuelas de pensamiento latinoamericana, consideran que los DDHH serían todos los derechos inherentes a la persona humana y por esa sola condición independiente de la existencia de una fuente jurídica que los reconozca. A su vez los DDFF serían aquel conjunto de DDHH, cuyo ejercicio no puede ser suspendido, sin garantías constitucionales y legales, ni menos en situaciones de un estado o situación de emergencia. ${ }^{17}$ En todo caso Pérez Luño nos expresa que hay una cierta tendencia- no absoluta- a

\footnotetext{
${ }^{12}$ LÓPEZ, cit. (n. 11), p. 14.

13 Agullar, Gonzalo, "El control de convencionalidad: Análisis en Derecho Comparado", Revista Direito GV (Sao Paulo), 2013, Vol. 9, n² 2, pp. 721-754.

${ }^{14}$ Angulo, Geofredo, Teoría contemporánea de los Derechos Humanos. Elementos para una reconstrucción sistémica, Editorial Dykinson, S.L., Madrid, 2015, p. 21.
}

15 Benda, Ernesto, "Dignidad Humana y derechos de la personalidad", en BendA, E.; MaIHofER, W.; Vogel, H.; Hesse, K.; Heyde, W. (coords.), Manual de Derecho Constitucional, Marcial Pons, Madrid, 2001, 2 edición, pp. 117-144. Adosa el publicista que al hacer supremo ese principio permite la alusión a derechos preexistentes de todos los hombres.

${ }^{16}$ Angulo, cit. (n. 14), pp. 156-157.

${ }^{17}$ Angulo, cit. (n. 14), pp. 156-157. 
reservar la formula DDFF para designar los derechos humanos positivados a nivel interno. En cambio, la fórmula DDHH es la más usual que se utiliza en las declaraciones y convenciones internacionales. ${ }^{18}$ Precisando sobre lo anterior, explica Angulo que los DDHH son exigencias ético-jurídicas cuyo acento moral hace de su violación, algo más que una simple transgresión de la legalidad. Solo en este sentido es posible entender que los DDHH adopten la consideración de límites al poder y criterio de legitimación política, es decir, la calificación moral del ejercicio del poder político. ${ }^{19}$

\section{El término y significado de la Ética}

La palabra ética proviene del griego ethos, que se entendió desde su origen como morada, lugar donde vivimos. Con posterioridad significó el carácter, el modo de ser, que una persona o grupo va desarrollando a lo largo de su vida. En todo caso la vida en tanto ethos puede y debe -para evitar una concepción estática- considerarse objeto de la ética. ${ }^{20}$ Como se explicó ut supra, a propósito de la moral, ética y moral poseen un significado etimológico casi idéntico. Así fueron empleados en la tradición filosófica. ${ }^{21}$

Podemos resumir entonces la ética, como todo aquello que se refiere al modo de ser o carácter adquirido, producto de poner en uso unas costumbres o hábitos considerados buenos. ${ }^{22}$ Ética entonces no es cualquier conducta, sino aquella que podemos aprobar en uso de un estándar cualquiera -idea o

\footnotetext{
${ }^{18}$ Pérez, Antonio, Derechos Humanos, Estado de Derecho y Constitución, Tecnos, Madrid, 2010, 10 edición, p. 33. En ese mismo sentido, AlEXy, Robert, Teoría de los derechos fundamentales. (Trad. de Carlos Bernal), Centro de Estudios Políticos y Constitucionales, Madrid, 2008, $2^{a}$ edición, p. 45, manifiesta en forma simple que las normas de derecho fundamental son aquellas que se expresan mediante disposiciones iusfundamentales, y las disposiciones iusfundamentales son exclusivamente los enunciados contenidos en la Ley Fundamental. Por su lado, Aguilar, Gonzalo, "Derechos Fundamentales-Derechos Humanos. ¿Una distinción válida en el siglo XXI?”, Boletín Mexicano de Derecho Comparado, 2010, n 127, pp. 15-71, https://revistas.juridicas.unam.mx/index.php/derecho-comparado/article/view/4594, consultada: 6 de noviembre de 2020, explica que no tiene razón de ser sostener hoy esta distinción entre DDFF y DDHH, si en definitiva el parámetro final de control de la actuación del Estado está construido por los DDHH y no por los DDFF. Además, los DDFF entendidos como DDHH positivados en la Constitución en realidad se complementan, pero también se subordinan a los DDHH.

${ }^{19}$ Angulo, cit. (n. 14), p. 89.

${ }^{20}$ Aranguren, José, Ética, Editorial Biblioteca Nueva, Madrid, 2009, p. 347.

${ }^{21}$ Tugendhat, Ernst, Lecciones de Ética, Gedisa, Barcelona, 1997, p. 36. Añade el autor, que se les denomina termini technici.
}

${ }^{22}$ Cortina y Martínez, cit. (n. 1), p. 21. 
criterio- previo, que poseemos acerca del bien. Se podría indicar entonces que Ética concierne al actuar humano correcto por referencia a cualquiera de los tres órdenes normativos de mayor uso. Esto es, los usos sociales, el derecho y la moral. Por ello se ha dicho que las normas de trato social, las jurídicas y las morales son todas normas éticas, puesto que todas ellas hacen referencia a distintos fines, y establecen qué es lo que debemos hacer para actuar correctamente, de un modo adecuado y no reprobable..$^{23}$

Precisemos, la ética y la moral son dos niveles de reflexión, de pensamiento y lenguaje diferentes, acerca de la acción moral. Esto quiere decir que denominamos moral a ese conjunto de valores, principios y normas que cada generación acuña y que transmite a la otra, en la confianza que es un buen legado de orientaciones sobre el modo como comportarse, para cultivar una vida buena y justa. En este caso a lo que ya aludimos: normas de trato social, normas morales y normas jurídicas. ${ }^{24}$ Por su lado singularizamos Ética, como aquella disciplina filosófica (Filosofía Moral) que se define como una reflexión de segundo orden sobre los problemas morales. Aclarando más, la moral se pregunta ¿qué debemos hacer? En cambio, la ética se pregunta en términos simples: ¿Qué argumentos avalan el código moral que aceptamos como guía de conducta? ${ }^{25}$ Más específico, la proyección de la razón sobre la moral es lo que los tratadistas denominan Ética, como un segundo orden de reflexión que tiene por objeto la moral, puesto que los juicios morales llevan implícita la exigencia de atender a la razón. Es decir, es una reflexión racional sobre la moral. ${ }^{26}$ La ética nos señalará qué concepción moral es la más razonable, a fin de que de esta forma podamos conducir nuestros comportamientos, es decir es una Ética cognitivista, pues los contenidos éticos pueden conocerse racionalmente. ${ }^{27}$

\footnotetext{
${ }^{23}$ SQUELLA, cit. (n. 3), pp. 61-62.

${ }^{24}$ Cortina y Martínez, cit. (n. 1), pp. 21-22.

${ }^{25}$ Cortina y Martínez, cit. (n. 1), pp. 21-22. Ahora bien, la Ética en este trabajo, la vamos a entender como aquella parte de la filosofía que estudia la reflexión sobre la moral. Los autores agregan que la Ética es un tipo de saber que aspira a constituirse racionalmente mediante los métodos de análisis de la filosofía. Cortina y Martínez, cit. (n. 1), p. 9.

${ }^{26}$ GonzÁLez, Juan Carlos, Diccionario de Filosofía, Biblioteca EDAF, Madrid, 2000, p. 176. En la misma línea, Cortina, Adela, Ética aplicada y democracia radical, Tecnos, Madrid, 2012, 6ª edición, p. 264. En efecto expone que lo moral también es racional. En cuanto entendemos por racionalidad la facultad de lo intersubjetivo; esto es la facultad que nos permite argumentar y alcanzar acuerdos.

${ }^{27}$ GONZÁLEZ, cit. (n. 26), pp. 176-177.
} 


\section{La ética aplicada. Origen y noción}

Es posible observar en la literatura, que desde finales del siglo XX se ha producido una proliferación de instrumentos diseñados para normar éticamente las actividades profesionales o laborales de las más diversas áreas. En ese entendido, las razones que explican la orientación de la Ética a la ética aplicada al menos son: a) pragmatismo (no peyorativo). Interesa que las cosas funcionen, que sirvan para algo (parte de nuestra cultura). La Ética no se salva de esa exigencia; b) la complejidad de las profesiones. Es decir, no sólo afecta cuestiones técnicas, sino que éticas. El ejercicio de las profesiones, exige no solo conocimientos, sino criterios sobre la justificación de fines y uso de medios. La técnica no se basta a sí misma; c) la desorientación. Ante la complejidad de la sociedad contemporánea y el cambio acelerado, que genera en las profesiones, parece que estamos en una situación que no sabemos que es ser buen médico, buen juez (el cumplir ciertas exigencias asociadas a un código compartido, puede ser una vía para cumplir ese objetivo, como es la ética judicial), buen ingeniero, entre otras profesiones. $^{28}$

En cuanto a la noción, se le ha denominado también ética práctica (aplicación de ética a temas prácticos, aborto eutanasia, etc.). ${ }^{29}$ Comprende una nueva forma de entender la Ética, que la acerque a las preguntas más acuciantes de la realidad actual, una nueva vía de conocimiento y de reflexión sobre los problemas morales y de proponer recomendaciones que orienten con garantías, la acción en las diversas actividades humanas, contribuyendo a moralizar de verdad el mundo de hoy ${ }^{30}$ Puntualizando que esta ética profesional, más que perfeccionar a la persona, tiende a lograr a la excelencia (puede lograr aquello el juez que ha tenido en consideración las virtudes que le mandata su código respectivo) en el quehacer profesional.

En síntesis, la moral se pregunta ¿qué debemos hacer? En cambio, la Ética, se pregunta en términos simples ¿qué argumentos avalan el código moral que aceptamos como guía de conducta? Por su lado, la ética aplicada comprende una nueva forma de entender la Ética, que la acerque a las

\footnotetext{
${ }^{28}$ AtienZA, Manuel, "Ética Judicial”, Jueces para la democracia (España), 2001, № 40, pp. 17-18, https://dialnet.unirioja.es/servlet/articulo?codigo=174851, consultada: 3 de octubre de 2018.

${ }^{29}$ Singer, Peter, Ética práctica, Cambridge University Press, Cambridge, 1995, 2 a edición, p. 1.

${ }^{30}$ PALACIOS, cit. (n. 10), p. 65.
} 
preguntas más acuciantes de la realidad actual.

\section{III. ÉTICA JUDICIAL. SU APLICACIÓN}

\section{Origen y noción}

En el ámbito Iberoamericano desde 1990 al menos hasta el día de hoy, se han celebrado más de catorce cumbres judiciales a la que se le ha dado importancia a la aplicación de la ética en el área judicial. Así se demuestra con la aprobación del Código Modelo Iberoamericano de Ética Judicial (Código IEJ). ${ }^{31}$

Cabe destacar que en el surgimiento de la ética judicial se unen a lo menos dos factores que son: a) subjetivo. El mundo judicial ha perdido homogeneidad (origen, ideología), lo que implica que el tema ético ocupa un papel visible, porque no hay acuerdo como resolver los problemas; $b$ ) objetivo. Esto tiene que ver con el aumento del poder judicial. Ello por el desarrollo de los sistemas jurídicos (Estado Constitucional de Derecho), que lleva a que los jueces controlen actuaciones que en el pasado pertenecerían al mundo político o bien el control de discrecionalidad administrativa. Esto además implica que como aplicadores de los derechos, utilicen principios y valores que suponen cierto grado de indeterminación. ${ }^{32}$

En cuanto a la noción, corresponde al marco de aplicación que se ha identificado como propio de los grupos profesionales o de personas que se dedican a la misma o parecida actividad, específicamente a todos los impartidores de justicia. ${ }^{33}$ En pocas palabras, se puede decir que la ética judicial es el principio básico de la acción correcta de los jueces. ${ }^{34}$ Es decir

\footnotetext{
${ }^{31}$ DíAz, Juan, "Ética Judicial”, en: SALDAÑa, J. (coord.), Ética Jurídica. Segundas Jornadas, UNAM, Instituto de Investigaciones Jurídicas, México D.F., 2015, p. 187, https://biblio.juridicas.unam.mx/bjv/ detalle-libro/3970-etica-juridica-segundas-jornadas, consultada: 25 de agosto de 2018. El Publicista aduce otros estatutos como Código de Conductas para funcionarios encargados de hacer cumplir la ley (1979); Principios básicos relativos a la Independencia de la Judicatura Milán 1985; Principios de Bangalore sobre la conducta judicial (2002); en la misma idea, Grande, Miguel, Ética de las profesiones jurídicas, Eds. Desclée De Brouwer, Bilbao, 2010, 2a edición, https://www.edesclee.com/img/cms/ pdfs/9788433020406.pdf, consultada: 10 de noviembre de 2018, p. 22.

${ }^{32}$ Atienza, cit. (n. 28), p. 17.

${ }^{33}$ AtienZa, cit. (n. 28), p. 17.

${ }^{34}$ Laноті, Shri RC, “Cánones de la ética judicial”, Nueva Delhi, 2005, 45 p., en línea: http://www.
} 
la ética judicial, tiene por propósito señalarle al juez exigencias que lo dirigirán a alcanzar esa plenitud o perfección como juez, alejándolo tanto de la maldad judicial como de la mediocridad..$^{35}$ Ahora bien, esa ética judicial que es lo que propone este artículo, es la que ha jugado un rol protagónico y es posible visualizarla en la aplicación del control cv (fase externa) que han realizado los jueces de la Corte IDH al dictar sus fallos.

\section{Alcances del Código Iberoamericano de Ética Judicial}

Si bien existen varios estatutos sobre los jueces, ${ }^{36}$ en el caso del Código $E I J,{ }^{37}$ este tiene como características de ser un compromiso institucional con la excelencia y un instrumento para fortalecer la legitimación del Poder Judicial. ${ }^{38}$ De lo que se trata es de alcanzar el mejor juez posible para nuestras sociedades, puesto que las normas éticas instan a la excelencia del trabajo del juez y al rechazo de la mediocridad. Este código consagra de una manera más completa los principios de la ética judicial iberoamericana. ${ }^{39}$

Vamos a destacar en este trabajo los principios de justicia, equidad y prudencia. Ello por cuanto el principio de motivación es perfectamente observable al leer cualquier sentencia de la Corte IDH. En todo caso como expresa Aristóteles en su Ética a Nicómaco, la virtud por excelencia no tiene lugar sin la prudencia. Por ello algunos afirman que todas las virtudes son especies de la prudencia. Es decir, todas las virtudes no se dan sin

judicialethics.umontreal.ca/en/codes\%20enonces\%20deonto/documents/CODE_iNDE.pdf, consultada: 25 de diciembre de 2018 (Traducción propia).

${ }^{35}$ VIGO, Rodolfo, "Ética y responsabilidad judicial", 2007, documento disponible en línea: http:// www2.scjn.gob.mx/red2/investigacionesjurisprudenciales/seminarios/3er-seminario-etica-judicial/ etica-judicial-su-especificidad-y-responsabilidad.pdf, consultada: 26 de octubre de 2018.

${ }^{36}$ Estatuto del Juez Iberoamericano (2001), artículos 37, 41 y 43; El Estatuto Universal del Juez de Taipéi (1999) que también establece los principios de independencia, autonomía, imparcialidad y sumisión a la ley.

${ }^{37}$ Poder judicial de Chile, Código Iberoamericano de Ética Judicial [2006], Poder Judicial República de Chile, Santiago, 2018. Sobre esta materia la Comisión Iberoamericana de Ética Judicial fue creada en la XIII Cumbre Judicial Iberoamericana celebrada en el año 2006 en República Dominicana. Destaca entre otros principios, el de independencia, imparcialidad, responsabilidad.

${ }^{38}$ CORTINA, cit. (n. 26), p. 271. Añade la autora que en la tradición comunitaria es excelente el que posee una habilidad en un grado superior a la media. Las virtudes son excelencias y ayudan a la supervivencia de la comunidad.

${ }^{39}$ Código Iberoamericano de Ética Judicial, cit. (n. 37), p. 7. 
prudencia. $^{40}$

En cuanto a los principios de justicia y equidad, prescribe en el artículo 35 del Código EIJ, que el fin último de la actividad judicial es realizar la justicia por medio del derecho. En el artículo 36, agrega que la exigencia de equidad deriva de la necesidad de atemperar con criterios de justicia las consecuencias personales, familiares o sociales desfavorables, surgidas por la inevitable abstracción y generalidad de las leyes. En su artículo 37, manifiesta que el juez equitativo es el que, sin transgredir el derecho vigente, toma en cuenta las peculiaridades del caso y lo resuelve basándose en criterios coherentes con los valores del ordenamiento y que puedan extenderse a todos los casos sustancialmente semejantes. En esa misma línea en su artículo 38, afirma que en la esfera de discrecionalidad que le ofrece el derecho, el juez deberá orientarse por consideraciones de justicia y equidad. Para terminar en el artículo 40, donde explicita que el juez debe sentirse vinculado no sólo por el texto de las normas jurídicas vigentes, sino también por las razones en las que ellas se fundamentan.

Respecto al principio de prudencia, en su artículo 69, acota que el juez prudente es el que procura que sus comportamientos, actitudes y decisiones sean el resultado de un juicio justificado racionalmente, luego de haber meditado y valorado argumentos y contraargumentos disponibles en el marco del derecho aplicable. Luego en su artículo 71, añade que al adoptar una decisión el juez, debe analizar las distintas alternativas que le ofrece el derecho y valorar las diferentes consecuencias que atraerán aparejadas cada una de ellas. ${ }^{41}$

Explicitemos que la racionalidad del derecho solo se comprende bien, cuando el derecho es una acción o práctica colectiva. El objeto de esa obra colectiva -de la que participarían constituyentes, legisladores, jueces y administradores - es el desarrollo del derecho vigente, como parte de un proceso todavía más amplio, como lo es el complejo de prácticas, instituciones, costumbres, actitudes culturales y creencias básicas que definen a una sociedad. ${ }^{42}$

En resumen, la ética judicial es el principio básico de la acción correcta

\footnotetext{
${ }^{40}$ Aristóteles, Ética a Nicómaco, Ediciones Mestas, Madrid, 2003, 2 ${ }^{\mathrm{a}}$ edición, pp. 153- 154.

${ }^{41}$ Código Iberoamericano de Ética Judicial, cit. (n. 37), artículos 19, 24, 35, 36, 37, 38, 40, 69 y 71.

${ }^{42}$ Cianciardo, Juan; Zambrano, Pilar, “¿Para qué sirve el derecho si incorpora la moral?, Revista Chilena de Derecho, 2015, Vol. 42, N² 2, pp. 615-648.
} 
de los jueces. Del mismo modo el Código IEJ consagra de manera más completa los principios de la ética judicial iberoamericana.

\section{CONTROL DE CONVENCIONALIDAD}

\section{Origen}

Existe un consenso preciso en doctrina en cuanto al desarrollo en virtud del cual se fue formando dicha institución. ${ }^{43}$ Cabe hacer notar, que hubo una etapa previa en la cual la primera mención del término control $c v$ aparece en la jurisprudencia de la Corte IDH por intermedio de un voto del juez Sergio García Ramírez al dictarse sentencia en el caso Myrna Mack Chang vs. Guatemala. ${ }^{44}$ Este tipo de control fue ejercido desde siempre por dicho tribunal..$^{45}$ Sin ser exhaustivo, también los autores están contestes en que se han sucedido varias etapas hasta el día de hoy en materia de evolución de la doctrina del control cv. Lo fundamental en este caso, es la etapa de pronunciamiento del Pleno de la Corte IDH en el caso Almonacid Arellano. ${ }^{46}$ En este pensamiento, la incorporación de este control $c v$ en la jurisprudencia de la Corte IDH encuentra su fundamento en la búsqueda por lograr que los tribunales de justicia de los Estados parte del sistema interamericano se sintieran involucrados y obligados a observar y cumplir lo establecido por el Pacto. ${ }^{47}$

\footnotetext{
${ }^{43}$ Mesa, Álvaro, "El control de convencionalidad: ¿un acto racional o irracional?, Estudios Constitucionales, 2018, No 1, p. 141, https://scielo.conicyt.cl/pdf/estconst/v16n1/0718-5200-estconst-16-01-00129.pdf, consulta: 20 de octubre de 2018.

${ }^{44}$ Corte IDH, caso Myrna Mack Chang con Guatemala. Sentencia de 25 de noviembre de 2003, voto razonado del juez García Ramírez, párrafo 27.

${ }^{45}$ Verbic, Francisco, "Control de Convencionalidad en el Sistema Interamericano de Protección de Derechos Humanos. Principales Características y Algunos Apuntes sobre su Aplicación en el Ordenamiento Jurídico Argentino", Ponencia, XXIII Jornadas Iberoamericanas de Derecho Procesal y I Conferencia Internacional sobre Procesos Colectivos, Buenos Aires, 2012: documento .pdf, en línea: http://www.academia.edu/3617712/Control_de_Convencionalidad_en_el_Sistema_Interamericano_de_ Protecci\%C3\%B3n_de_Derechos_Humanos._Principales_Caracter\%C3\%ADsticas_y_Algunos_Apuntes_ sobre_su_Apl, consultada: 28 de octubre de 2018.

${ }^{46}$ Corte IDH, caso Almonacid Arellano y otros con Chile, Sentencia de 26 de septiembre de 2006, párrafo 124.

${ }^{47}$ Verbic, cit. (n. 45), p. 6.
} 
Por otro lado, hay que destacar que la Corte IDH, a partir del caso Almonacid Arellano y otros vs. Chile, fallado el 26 de septiembre de 2006, ha dictado desde esa fecha a agosto del año 2020, más 185 sentencias en casos contenciosos. Del mismo modo, al menos en 40 de ellas se mencionó la voz control $c v$, se señaló su destinatario, la forma de su ejercicio, el parámetro y objeto del control de convencionalidad. ${ }^{48}$ Ahora bien, respecto al desarrollo del control $c v$, es en sus primeras etapas donde se construyen los principales aspectos. Ello sin perjuicio como se apreciará en el análisis de su jurisprudencia, que este control $c v$ se ha ido enriqueciendo con otros elementos. ${ }^{49}$

\section{Noción}

La doctrina del control $c v$ puede definirse como el mecanismo que utiliza la Corte IDH tanto en sede contenciosa como consultiva para determinar la compatibilidad o no del derecho interno o los actos de los agentes de un Estado, con las disposiciones de la CADH. ${ }^{50}$ Esta fase denominada "externa", como se ha indicado precedentemente, es la que explicita este artículo.

Por otro lado, la doctrina del control $c v$, establece una obligación internacional respecto de todas las autoridades de los Estados parte de la $\mathrm{CADH}$, de interpretar cualquier norma nacional (constitución, ley, decreto, reglamento, jurisprudencia, etc.) en conformidad con la CADH y en general con el Corpus Iuris Interamericano (bloque de convencionalidad). Luego si existe una manifiesta incompatibilidad entre dicho Corpus Iuris, las autoridades estatales deben abstenerse de aplicar la norma nacional para

\footnotetext{
${ }^{48}$ Henríquez, Miriam; morales, Mariela, "Presentación”, en: Henríquez, M.; Morales, M. (coords.), El Control de Convencionalidad: Un balance comparado a 10 años de Almonacid Arellano vs. Chile, DER Ediciones, Santiago de Chile, 2017, pp. 5-14; en el mismo sentido: VIo, Eduardo, "Jurisprudencia de la Corte Interamericana de Derechos Humanos: ¿del control de convencionalidad a la supranacionalidad?" en: Steiner, Christian (ed.) Anuario de Derecho Constitucional Latinoamericano 2015, Konrad Adenauer Stiftung, Bogotá, 2015, pp. 93-112.

${ }^{49}$ NAsh, Claudio, Derecho Internacional de los Derechos Humanos en Chile. Recepción y aplicación en el ámbito interno, Universidad de Chile - Centro de Derechos Humanos, Santiago, 2012, pp. 59-60.

${ }^{50}$ García, Gonzalo, "Preguntas esenciales sobre el control de convencionalidad difuso aplicables a Chile", en: NogueIra, H. (coord.), La protección de los Derechos Humanos y fundamentales de acuerdo a la Constitución y el Derecho Internacional de los Derechos Humanos, Librotecnia, Santiago de Chile, 2014, pp. 356-357.
} 
evitar la vulneración de DDHH (fase interna). ${ }^{51}$

El denominado control $c v$ se ha ido convirtiendo en uno de los motores del constitucionalismo transformador. En efecto, es a su vez puente y vehículo de confluencia e interacción entre el derecho doméstico y el derecho internacional para dar mejor y mayor protección de los DDHH y el robustecimiento de las democracias y el Estado de Derecho. ${ }^{52}$

A modo de síntesis, el control cv es un mecanismo de la Corte IDH para determinar la compatibilidad de los actos de un Estado, con disposiciones de la CADH. El control $c v$ se ha ido convirtiendo en uno de los motores del constitucionalismo transformador.

\section{V. ÉTICA Y CONTROL DE CONVENCIONALIDAD}

\section{Aproximación}

Observando los vínculos que existen entre Ética y control cv (en su fase externa) se ha sostenido el sustrato moral de las obligaciones jurídicas. Un ejemplo de ello es la Declaración Americana de los Derechos y Deberes del Hombre de $1948 .{ }^{53}$ Instrumento, al que permanentemente se le ha dado un carácter vinculante y no sólo moral y político. Así, en su preámbulo expone que los deberes de orden jurídico presuponen otros, de orden moral, que los apoyan conceptualmente y los fundamentan. En esa misma línea todo el régimen internacional de la defensa de los DDHH gira sobre la base del dogma de la dignidad humana; que de inicio no es una afirmación jurídica, sino ética. Luego, en realidad la Ética y el derecho tienen la misma convicción humanista, esto es, la persona humana como pilar de la existencia. El objetivo además es el mismo, proteger al ser humano, darle

\footnotetext{
${ }^{51}$ Mac-Gregor, Eduardo, "El Control de Convencionalidad en la Jurisprudencia de la Corte Interamericana de Derechos Humanos (a una década de su creación: 2006-2016)", en: Henríquez, M.; Morales, M. (coords.), El Control de Convencionalidad: Un balance comparado a 10 años de Almonacid Arellano vs. Chile, DER Ediciones, Santiago de Chile, 2017, pp. 37-66.

52 Von bogdandy, Armín, "Prólogo", en: Henríquez, M.; Morales, M. (coords.), El Control de Convencionalidad: Un balance comparado a 10 años de Almonacid Arellano vs. Chile, DER Ediciones, Santiago de Chile, 2017, pp. 1-4.

${ }^{53}$ Declaración Americana de los Derechos y Deberes del Hombre (1948).
} 
seguridad y dignidad. ${ }^{54}$

Por su lado respecto a los DDHH -y esto es esencial, pues tienen que ver con la aplicación del control $c v$ (fase externa)- son el lugar de encuentro en que se cruzan los senderos de la Ética, la política y del derecho. Por ello su fuerza y densidad conceptual. ${ }^{55}$ Profundizando, la mirada ética de los DDHH, manifiestan siempre un inconformismo. Revelan un aspecto insatisfecho, en cuanto hay algo que no se ha alcanzado. ${ }^{56}$

En ese sentido los actores deben actualizar el contenido ético que mandata ese orden jurídico respectivo, en forma constante. Más aún, el hecho que en un Estado Democrático y de Derecho los tribunales han de refrendar su legitimidad (no sólo aplicando la ley) sino a través de una actuación apegada a ciertos parámetros éticos, pues si no se observan estos parámetros hay una ilegitimidad manifiesta. ${ }^{57}$ Como se aprecia esto se adecua en forma precisa con lo expresado en el resumen al inicio de este artículo, esto es, la ética puede darnos una orientación racional moral sobre un código moral que nosotros hemos elegido. Código moral que se explica a continuación y que los jueces de la Corte IDH sin duda, por la labor que ejercen, adhieren a él y lo aplican y aplicaron en la jurisprudencia que se analiza en este trabajo.

\section{Una propuesta de código moral básico}

En este apartado, se propone y explica un código moral básico, pues de otra forma no podría realizarse una orientación racional moral desde la Ética. Comprende al menos, a nuestro juicio un conjunto de valores, principios y normas que se integran de la siguiente forma: a) un conjunto de instrumentos internacionales elementales, que se explican a continuación; b) opinión consultiva de la Corte $\mathrm{IDH},{ }^{58}$ en la cual los Estados se someten

\footnotetext{
${ }^{54}$ García, Sergio, Temas de Derecho, Universidad Autónoma del Estado de México, México, 2002, p. 580.

${ }^{55}$ Instituto DE DEREChos humanos BARTOlomé De las CASAS, "Los Derechos Humanos en el contexto Ético, Jurídico y Político", Madrid, 2010, documento .pdf, http://www.tiempodelosderechos.es/docs/ dic10/dhcontexto.pdf, consultada: 20 de octubre de 2018, p. 2.

${ }^{56}$ INSTITUTO DE DERECHOS HUMANOS BARTOLOMÉ DE LAS CASAS, cit. (n. 55), p. 3.

${ }^{57}$ SAldaÑa, Javier, Ética Judicial. Virtudes del Juzgador, Suprema Corte de Justicia de la Nación, México D.F., 2007, 124 p., https://sistemabibliotecario.scjn.gob.mx/sisbib/2018/000291845/000291845.pdf, consultada: 25 de noviembre de 2018.

${ }^{58}$ Opinión Consultiva OC-2/82 de 1982. Este documento de la Corte IDH, nos expresa que los tratados
} 
a un orden legal dentro del cual ellos, por el bien común, asumen varias obligaciones, no en relación con otros Estados, sino hacia los individuos bajo su jurisdicción; c) el control cv como obligación de garantía, es decir, este control se enmarca dentro de un instituto que es el control internacional. Esto es, aquel conjunto de procedimientos y técnicas creadas y destinadas a verificar si el comportamiento de los Estados se adecua o no a lo exigido por normas de conducta internacionales; ${ }^{59}$ d) el Código IEJ, ampliamente desarrollado. El que describe una serie de principios antes explicados. Principios que obviamente deben tener en cuenta los numerales anteriores que se han incorporado como parte del código moral. Esta es entonces la matriz en virtud del cual los jueces de la Corte IDH han trabajado las sentencias que se detallarán con posterioridad al aplicar el control cv (fase externa). Y en esa fase estos jueces han dado aplicación a la ética judicial. Ahora corresponde explicar lo expuesto en la letra a).

\section{Conjunto de instrumentos internacionales elementales}

Es posible afirmar que esos valores, principios y normas que se encuentran en los grandes textos internacionales, a medida que pasan los años se han revelado como el gran código universal de conducta de la sociedad humana. ${ }^{60}$ Sin perjuicio de las dificultades para aprobar la Declaración Universal de Derechos Humanos y los dos pactos, de Derechos Económicos Sociales y Culturales, y el de Derechos Civiles y Políticos; lo que se buscó fue dar a los derechos que la Declaración tutela, que estos

modernos sobre derechos humanos, en especial la Convención Americana, no son del tipo tradicional, sino que su objeto y fin son la protección de los derechos fundamentales de los seres humanos. Luego, al aprobar estos tratados sobre derechos humanos, los Estados se someten a un orden legal dentro del cual ellos, por el bien común, asumen varias obligaciones, no en relación con otros Estados, sino hacia los individuos bajo su jurisdicción.

${ }^{59}$ NúÑEz, Constanza, El control de convencionalidad en la jurisprudencia de la Corte Interamericana de Derechos Humanos, ARA Editores, Buenos Aires, 2017, p. 36. Este control es una expresión de la obligación de garantía y de disponer medidas en el ámbito interno. Esto implica que el control cv cristaliza estas obligaciones para toda autoridad pública. Más aun, dicho control desde una mirada más amplia se enmarca dentro de un instituto que es el control internacional. Esto es, aquel conjunto de procedimientos y técnicas creadas y destinadas a verificar si el comportamiento de los Estados se adecua o no a lo exigido por normas de conducta internacionales.

${ }^{60}$ González, Nazario, Los Derechos Humanos en la Historia, Alfaomega, México, 2002, p. 210. 
tuvieran una fuerza vinculante indiscutible. ${ }^{61}$

Para realizar este apartado, hemos elegido como fecha de inicio, la constitución de Naciones Unidas de 1945 y luego los demás textos normativos a partir de la Declaración Universal indicada de 1948. Los aludidos instrumentos que se han elegido más que otros, representan una visión inicial y luego más acabada de los DDHH de hombres y mujeres. Esto lo vamos a desarrollar de la siguiente manera: a) citaremos en lo pertinente cartas, declaraciones y pactos del Sistema de Naciones Unidas; b) cartas, declaraciones y pactos del Sistema Interamericano.

Los parámetros que se van a considerar al observar estos textos son:

(i) La mención de la dignidad en su preámbulo y/o Introducción. Dignidad de la cual ya hemos hecho referencia;

(ii) Obligaciones que deben cumplir los Estados, en lo pertinente, pactos y convenios. Esto puede resumirse, hoy en el compromiso que los Estados asumen al aprobar una declaración o adherir o ratificar un pacto, es decir, la obligación de cumplimiento se traduce en 3 obligaciones principales, que consisten en respetar, garantizar y no discriminar. ${ }^{62}$

(iii) Cláusula interpretativa de protección de los derechos y libertades protegidos. Esto puede resumirse de manera similar - con los cambios de perfección normativo en el tiempo- para todos los pactos de la siguiente forma:

iii.1) ninguna disposición del pacto respectivo puede ser interpretada en el

${ }^{61}$ Truyol, Antonio, Los Derechos Humanos, Tecnos, Madrid, 1982, 3a edición, pp. 26-33; en la misma perspectiva, GonZÁLEZ, cit. (n. 60), pp. 169-186; y PÉrEZ, cit. (n. 18), p. 27. Este último afirma que una de las reuniones de la UNESCO cuando se discutía sobre los derechos del hombre, alguien se admiraba que se encontraran de acuerdo en una lista de derechos, personas ideológicamente contrarias. Ello con la condición de que no se les pregunte el porqué. Asimismo, GARCíA, Javier, "El Preámbulo contexto hermenéutico del Convenio: Un instrumento constitucional del orden público europeo", en: GARCíA, J. y Santolaya, P. (coords.), La Europa de los derechos. El Convenio Europeo de Derechos Humanos, Centro de Estudios Políticos y Constitucionales, Madrid, 2009, $2^{\text {a }}$ edición, pp. 25-53. Con relación al preámbulo del Convenio Europeo de DDHH, añade que se evidencia la existencia de una herencia común de tradiciones culturales y constitucionales en el lenguaje de los derechos y libertades de entre los cuales sobresale la preeminencia del derecho.

${ }^{62}$ MesA, cit. (n. 43), pp. 152. Respetar, consiste en cumplir directamente con la conducta establecida en cada norma convencional, ya sea absteniéndose de actuar o dando una prestación. Garantizar se traduce en la obligación que asume el Estado de promover, a través de sus órganos, la posibilidad real y efectiva de que sus ciudadanos ejerzan los derechos y disfruten las libertades que se les reconocen. No discriminar es una obligación general el deber del Estado de no discriminar a las personas en el goce y ejercicio de sus derechos. 
sentido de permitir a alguno de los Estados Partes, grupo o persona, suprimir el goce y ejercicio de los derechos y libertades reconocidos en él o limitarlos en mayor medida que el pacto haya previsto;

iii.2) limitar el goce y ejercicio de cualquier derecho o libertad que pueda estar reconocido, de acuerdo con las leyes de cualquiera de los Estados Partes o de acuerdo con otra convención en que sea parte uno de dichos Estados.

(iv) Se hace alusión en forma específica al Estatuto de la Corte Internacional de Justicia, para observar como la comunidad jurídica internacional ha acordado resolver los conflictos al menos desde 1945, en conformidad al derecho internacional aplicando las convenciones internacionales, la costumbre internacional, los principios generales de derecho reconocidos por las naciones civilizadas. Y en cuanto al Convenio de Viena sobre Derecho de los Tratados, esto es, para verificar cómo los Estados deben cumplir los tratados a los cuales adhieren. Explicando que los principios del libre consentimiento, de la buena fe y la norma pacta sunt servanda están universalmente reconocidos. Explicita este pacto que las controversias relativas a los tratados, al igual que las demás controversias internacionales, deben resolverse por medios pacíficos y de conformidad con los principios de la justicia y del derecho internacional. Si bien estos dos documentos, son parte del sistema de Naciones Unidas, es posible considerarlo para ambos sistemas, en relación a lo expuesto.

(1) Del Sistema de Naciones Unidas. Los instrumentos se abrevian como se indica a continuación: Carta de Constitución de Naciones Unidas de 1945 (Carta ONU, artículos 1 y 2); ${ }^{63}$ Estatuto de la Corte Internacional de Justicia de 1945 (Estatuto CIJ, artículo 38); ${ }^{64}$ Declaración Universal de Derechos Humanos de 1948 (DUDDHH); ${ }^{65}$ Convención Internacional sobre Eliminación de Todas las Formas de Discriminación Racial de 1965 (CIEFDR, artículos 1 y 2); ${ }^{66}$ Pacto Internacional de Derechos Económicos, Sociales y Culturales de 1966 (PIDESC, artículos 2 y 24); ${ }^{67}$

\footnotetext{
${ }^{63}$ Carta de Naciones Unidas (1945). Artículos 1 y 2.

${ }^{64}$ Estatuto de la Corte Internacional de Justicia (1945). Artículo 38.

${ }^{65}$ Declaración Universal de Derechos Humanos (1948).

${ }^{66}$ Convención Internacional sobre Eliminación de todas las formas de discriminación racial (1965). Artículo 1 y 2.

${ }^{67}$ Pacto Internacional de Derechos Económicos, Sociales y Culturales (1966). Artículos 2 y 24.
} 
Pacto Internacional de Derechos Civiles y Políticos de 1966 (PIDCP, artículos 2 y 22) ${ }^{68}$ Convención sobre la Eliminación de Todas las Formas de Discriminación contra la Mujer de 1979 (CEFDM, artículos 2 y 23); ;9 Convención contra la Tortura y otros Tratos o Penas Crueles, Inhumanos o Degradantes de 1984 (CCTTPCID, artículos 1, 2, 10, 16); ${ }^{70}$ Convención sobre los Derechos del Niño de 1989 (CDN, artículos 2 y 41); $;^{71}$ Convención de Viena sobre Derecho de los Tratados de 1969 (Convenio VDTT, artículos $26,27$ y 31$).^{72}$

(2) Del Sistema Interamericano. Los textos se resumirán como se indica a continuación: Carta de Constitución de la Organización de Estados Americanos de 1948 (Carta OEA); $;^{73}$ Declaración Americana de los Derechos y Deberes del Hombre de 1948 (DADDDH) $7^{74}$ Convención Americana sobre Derechos Humanos de 1969 (CADH, artículos 1, 29 y $38) ;{ }^{75}$ Convención Interamericana para Prevenir y Sancionar la Tortura de 1985 (CIPST, artículos 1 6, 15 y 16) $;{ }^{76}$ Convención Interamericana para Prevenir, Sancionar y Erradicar la Violencia contra la Mujer -Convención de Belem do Pará- de 1995 (CIPSEVCM, artículos 4, 7, 13 y 14). ${ }^{77}$

Es decir, en cada texto citado hay una reiteración y unión robusta a través de los años de estos parámetros, en especial en la CADH.

En síntesis, la Ética y el Derecho tienen la misma convicción humanista, esto es, la persona humana como pilar de la existencia. Conceptos que se aprecian en la descripción de este Código.

\footnotetext{
${ }^{68}$ Pacto Internacional de Derechos Civiles y Políticos (1966). Artículos 2 y 22.

${ }^{69}$ Convención sobre la Eliminación de todas las formas de discriminación contra la mujer (1979). Artículos 2 y 23.

${ }^{70}$ Convención contra la Tortura y otros tratos o penas crueles, inhumanos o degradantes (1984). Artículos $1,2,10$ y 16.

${ }^{71}$ Convención sobre los derechos del niño (1989). Artículos 2 y 41.

${ }^{72}$ Convenio de Viena sobre derecho de los tratados (1969). Artículos 26, 27 y 31.

${ }^{73}$ Carta de Organización de Estados Americanos (1945).

${ }^{74}$ Declaración Americana de Derechos y Deberes del Hombre (1948).

${ }^{75}$ Convención Americana sobre Derechos Humanos, Pacto de San José de Costa Rica (1969), Artículos 1, 29 y 38.

${ }^{76}$ Convención Interamericana para prevenir y sancionar la tortura (1985). Artículos 1, 6,15 y 16.

${ }^{77}$ Convención Interamericana para prevenir, sancionar y erradicar la violencia contra la mujer (1995). Artículos 4, 7, 13 y 14.
} 


\section{JURISPRUDENCIA RELEVANTE SOBRE EL CONTROL DE CONVENCIONALIDAD DE LA CORTE IDH}

\section{Antecedentes previos para considerar una orientación racional moral desde la Ética.}

La fundamentación normativa de la institución del control $\mathrm{cv}$-como explica Nash- ${ }^{78}$ está asentada. En efecto, en la normativa internacional se basa en la observación conjunta de los artículos 1.1, 2 y 29 de la CADH. ${ }^{79}$ De su lectura se desprende que la protección de los DDHH debe ser guía en la actuación de los Estados. No obstante esa fundamentación normativa, al momento de analizar la jurisprudencia relevante, según se ha dicho precedentemente, en la que la Corte IDH se ha pronunciado sobre la doctrina del control $c v$ (fase externa) debemos considerar desde la mirada de la Filosofía Moral (Ética), lo que se propuso como código moral básico antes estudiado, pues va a constituir uno de los deberes que debe cumplir un juez para concretar la excelencia y alejarse de la mediocridad y de esta forma realizar una elección racional ética y darle contenido a la ética judicial. Como se explicó precedentemente al aplicar los principios del Código IEJ, los jueces de la Corte IDH deben tener en consideración en su decisión final el código moral básico aludido, puesto que, desde la mirada de la Ética, corresponde a una orientación racional moral que se adecua a la evolución que ha tenido la protección de los DDHH y en especial lo que consagra la misma CADH.

\section{Análisis de jurisprudencia relevante.}

Se han seleccionado sentencias de ocho casos (dentro de muchos otros), por la importancia de su doctrina, a propósito del control $c v$, según nuestra propuesta. Del mismo modo, de los principios del Código IEJ se han elegido la justicia, la equidad y la prudencia. Principios que en su aplicación por la Corte IDH, como se ha explicitado, y en una orientación racional moral desde la ética, van a integrar - porque así lo demandan estos principios- lo que hemos puntualizado como código moral básico.

\footnotetext{
${ }^{78}$ NASH, cit. (n. 49), pp. 54-56.

${ }^{79}$ Convención Americana sobre Derechos Humanos, cit. (n. 75). Artículos $1^{\circ}, 2^{\circ}$ y 29.
} 
a) Almonacid Arellano y otros vs. Chile (2006). ${ }^{80}$

En el párrafo sobre control de convencionalidad -párrafo 124- la Corte IDH se pronunció sobre la doctrina del control $c v$ por primera vez en pleno y expresó que los jueces y tribunales internos no sólo están sujetos al imperio de la ley, sino que cuando un Estado ha ratificado un tratado internacional como la $\mathrm{CADH}$, sus jueces también están sometidos a esas disposiciones. Luego, al aplicar el derecho vigente les obliga a velar por que los efectos de las disposiciones de la Convención no se vean mermadas por la aplicación de leyes contrarias a su objeto y fin, y que desde un inicio carecen de efectos jurídicos. Es decir, el Poder Judicial debe ejercer una especie de control $c v$ entre las normas jurídicas internas que aplican en los casos concretos y la CADH. Además, en este ejercicio el Poder Judicial debe tener en cuenta no solamente el tratado, sino también la interpretación que del mismo ha hecho la Corte Interamericana, intérprete última de la Convención Americana.

Lo que podemos deducir en este fallo modelo, es que hay una mirada global de la Corte IDH, recordando nuevamente la opinión consultiva citada. Además, que la aplicación del derecho, significa un examen total de las normas sobre la materia. Implica una revisión del derecho y sus prácticas internas en relación a lo que dispone la CADH y la interpretación que de ella ha realizado la Corte IDH. El derecho es dinámico, las normas sobre DDHH deben ser actualizadas, nuestras prácticas deben ser revisadas. La Corte IDH marcará un hito al decirnos que hay que buscar el mejor derecho, la mejor interpretación, en términos más técnicos, el mejor estándar normativo de derechos humanos. Esto va a constituir, en las dos primeras décadas del siglo XXI, la mayor manifestación ética para la protección de los $\mathrm{DDHH}$ realizada por la Corte IDH. Esto es, sin duda, una expresión precisa de los principios de justicia, equidad y prudencia antes expuestos, es decir, aplicación concreta de la ética judicial.

b) Boyce y otros vs. Barbados (2007). ${ }^{81}$

En el párrafo 78 de la sentencia de dicho caso, señala la Corte IDH que el Comité Judicial del Consejo Privado (CJCP) realizó un análisis

\footnotetext{
${ }^{80}$ Corte IDH, Almonacid Arellano y otros con Chile, cit. (n. 46), párrafo 124.

${ }^{81}$ Corte IDH, caso Boyce y otros con Barbados. Sentencia de 20 de noviembre de 2007, párrafo 78.
} 
puramente constitucional, y lo cierto es que debió haber analizado si la ley también era convencional, es decir, tanto el CJCP y la Corte de Justicia del Caribe (máximo órgano jurisdiccional en sede local) deben decidir si la ley de Barbados viola los derechos reconocidos en la Convención. Para luego repetir la doctrina de Almonacid Arellano. Es posible argumentar en base a lo ya razonado en la sentencia anterior, que la Corte IDH vuelve nuevamente sobre el principio fundamental de justicia y equidad, en cuanto los Estados parte, en este caso el Poder Judicial, debe revisar la aplicación del derecho y las prácticas jurisdiccionales de una manera global en conformidad a las normas de la CADH y la jurisprudencia de la Corte IDH. La racionalidad de nuestras actuaciones implica verificar por todos los medios posibles si realmente nuestro derecho interno se adecua a los contenidos de la $\mathrm{CADH}$ y la jurisprudencia de la Corte IDH. Nuevamente, un ejercicio práctico de la ética judicial.

c) Cabrera García y Montiel Flores vs. México. (2010). ${ }^{82}$

En sus párrafos 225 a 232, la Corte IDH reitera -ya avanzado los años- el criterio de Almonacid Arellano, pero precisando que ese control de convencionalidad lo deben ejercer los jueces y órganos vinculados a la administración de justicia en todos los niveles. Hay una apertura hacia los tribunales constitucionales. Del mismo modo, en los párrafos posteriores, pensando en esta aplicación del derecho de manera integral, y en especial en aplicar siempre el mejor estándar normativo en materia de DDHH, da cuenta cómo diferentes tribunales o salas constitucionales de los diferentes Estados Parte han efectuado este control de convencionalidad, teniendo en cuenta las interpretaciones efectuadas por la Corte IDH.

Como es posible observar, la orientación racional - moral que guía a la Corte IDH, es una visión global de interpretación, revisión y aplicación del derecho. Esto significa que, tal como lo expresa el Código IEJ, no puede haber una actuación mediocre al momento de administrar justicia. Las diferentes Cortes de los demás Estados Parte deben llegar a la convicción que las interpretaciones de la Corte IDH, representan un mejor derecho. Expresión sin duda de considerar los principios de justicia, equidad y

${ }^{82}$ Corte IDH, caso Cabrera García y Montiel Flores con México. Sentencia de 26 de noviembre de 2010, párrafos 225 a 232 . 
prudencia. Es decir, holística aplicación de la ética judicial.

d) Gelman vs. Uruguay (2011). ${ }^{83}$

Especialmente en sus párrafos 193 y 239: en el 193 la Corte IDH repite el criterio actualizado de Almonacid Arellano. Luego, en el 239 realiza un nuevo aporte en cuanto la Corte IDH, pensando en la realización de la justicia por medio del derecho en la toma de conciencia de los Estados Parte en la aplicación de la $\mathrm{CADH}$, va a incorporar como órgano competente para realizar dicho control a toda autoridad pública, es decir, ampliando desde el Poder Judicial a todos los órganos públicos. En este caso el principio de justicia alcanza una mayor extensión, toda vez que expresó que la sola existencia de un régimen democrático, no garantiza per se el permanente respeto, en este caso específico, del derecho internacional de los derechos humanos, puesto que la protección de los DDHH constituye un límite infranqueable a las reglas de la mayoría, en los cuales, y esto es lo valioso desde un punto de vista ético, debe primar siempre un control de convencionalidad. Manifestación amplia y precisa entonces de los principios de justicia, equidad y prudencia, para mejor defensa de los DDHH. Reitera un uso integral de la ética judicial.

e) Masacres de Río Negro vs. Guatemala (2012). ${ }^{84}$

Especialmente en sus párrafos 142 y 262: en el 142, la Corte IDH amplía para los efectos del control cv, lo que los Estados Parte deben realizar y en este caso respecto a la protección especial que todo niño por su desarrollo físico y emocional necesitan. El Estado debe asumir una posición especial de garante, tomando medidas especiales orientadas en el principio del interés superior del niño. Principio que se fundamenta en la dignidad misma del ser humano. Aquí nuevamente en esta mirada global del derecho, la Corte IDH va a enriquecer el control de convencionalidad, indicando que tanto la $\mathrm{CADH}$ como la CDN forman un Corpus Iuris Internacional de protección de los niños, que sirve para fijar el contenido y alcance del

\footnotetext{
${ }^{83}$ Corte IDH, Gelman con Uruguay, sentencia de 24 de febrero de 2011, párrafos 193 y 239.

${ }^{84}$ Corte IDH, Masacres de Río Negro con Guatemala, sentencia de 4 de septiembre de 2012, párrafos 142 y 262.
} 
artículo 19 de la Convención Americana.

En esa misma idea de razonamiento, en el párrafo 262, la Corte IDH va a indicar que cuando un Estado es parte de tratados internacionales como la Convención Americana sobre Derechos Humanos, la Convención Interamericana sobre Desaparición Forzada de Personas, la Convención Interamericana para Prevenir y Sancionar la Tortura, y la Convención Interamericana para Prevenir, Sancionar y Erradicar la Violencia Contra la Mujer, dichos tratados obligan a todos sus órganos, incluido el Poder Judicial, cuyos miembros deben velar por que los efectos de las disposiciones de dichos tratados no se vean mermados por la aplicación de normas o interpretaciones contrarias a su objeto y fin. Reiterando luego el holding Almonacid Arellano. Puntualiza, además, que en el control de convencionalidad no sólo hay que tener en cuenta la $\mathrm{CADH}$, sino los demás instrumentos interamericanos como la interpretación que de éstos ha hecho la Corte IDH. Como puede observarse, pensando en las orientaciones racionales para obrar moralmente, el juez debe estudiar todo el derecho aplicable, integrar los demás tratados según interpretación que ha realizado la Corte IDH, dando en su caso, las razones jurídicas válidas para ello, como sucedió en esta causa. La elección del mejor derecho y la mejor interpretación significa visualizar los mejores estándares normativos de DDHH que también ofrecen los demás instrumentos internacionales. Una nueva demostración de la aplicación de los principios de justicia, equidad y prudencia. Insiste en una robusta aplicación de la ética judicial.

f) J. vs. Perú (2013). ${ }^{85}$

La Corte IDH, en el párrafo 407, va a reiterar el criterio Almonacid Arellano, pero va a insistir -como lo había reiterado con anterioridad- en cuanto a la obligación comprendida en el artículo 2 de la CADH, en el sentido de la supresión o expedición de normas en conformidad a los estándares de la Convención. En este caso va a ahondar y destacar que en la aplicación del derecho se requiere el desarrollo de prácticas estatales conducentes a la observancia efectiva de los derechos y libertades consagrados en la misma convención, en cuanto la aplicación de normas o su interpretación (practica jurisdiccional) debe estar ajustado al mismo fin que persigue el artículo 2.

${ }^{85}$ Corte IDH, J. con Perú, sentencia de 27 de noviembre de 2013, párrafo 407. 
Este fallo es de la mayor importancia, puesto que los Estados Parte a través de sus órganos, en este caso todos los órganos vinculados a la actividad jurisdiccional, no pueden omitir en su labor jurisdiccional, lo que establece la CADH y la jurisprudencia de la misma Corte IDH, sino que deben realizar una revisión integral del derecho aplicable, de forma tal que permita el efectivo respecto, garantía y no discriminación de los derechos consagrados en la convención y en los tratados que ha indicado la Corte IDH en el denominado Corpus Iuris Interamericano. Para de esta forma realizar por medio del derecho el valor justicia. Es en esta sentencia- más que en cualquiera de las revisadas- se fija con mayor fuerza una orientación racional moral de cómo debemos realizar nuestras prácticas judiciales. Una expresión nítida de la aplicación de los principios de justicia, equidad y prudencia. Manifiesta una vez más la importancia de utilizar como herramienta la ética judicial.

\section{g) San Miguel Sosa y otras vs. Venezuela (2018). ${ }^{86}$}

Especialmente en sus párrafos 191 y 192. Esta sentencia enriquece el control $c v$ respecto a la aplicación e interpretación del derecho. En efecto, en el 191 se sostiene que, si bien en la actuación de las autoridades hay una presunción de comportamiento conforme a derecho, debe verificarse si esa actuación es arbitraria o es una desviación de poder. Es decir, si hay un motivo distinto al de la norma que le otorga potestades a dicha autoridad. Esto -alude la Corte- es parte del control de convencionalidad. En el 192 explica que, ante alegatos de persecución o discriminación política, represalias encubiertas o restricciones arbitrarias indirectas al ejercicio de una serie de derechos, los jueces estaban en posición y obligación, por control de convencionalidad, de garantizar una protección judicial con las debidas garantías a las presuntas víctimas, analizando la motivación o finalidad real del acto impugnado más allá de las razones formales invocadas por la autoridad recurrida.

Este nuevo aporte, como lo ha hecho en todos los fallos analizados, es una nueva expresión de la idea de que tenemos orientaciones racionales morales para actuar, como es la protección de los derechos y libertades

${ }^{86}$ Corte IDH, San Miguel Sosa y otras con Venezuela, sentencia de 8 de febrero de 2018, párrafos 191 y 192. 
contenidos en la CADH y el Corpus Iuris aludido. Esto no es a partir de voluntarismo o subjetivismo, sino de los estándares normativos que establece la propia CADH y la interpretación que de ella ha realizado la Corte IDH en conformidad a un Corpus Iuris Interamericano, que ya se ha explicado. Por ello, en este caso, sin duda hay una aplicación más profunda -que en otros fallos- de la ética judicial, porque exhorta a los órganos jurisdiccionales a verificar en la situación en que se encuentra el denunciante, cuando no puede aportar pruebas directas o se encuentre en una situación desmedrada. No es posible quedarse en la formalidad de la aplicación del derecho, si hay instrumentos para resolver mejor el caso. Manifestación precisa de la aplicación de los principios de justicia, equidad y prudencia. Como se observa, sólo la ética judicial, nos permite un adecuado razonamiento y decisión para cada caso.

\section{h) Urrutia Labreaux vs. Chile (2020). ${ }^{87}$}

La Corte IDH, en los párrafos 93 y 94 de esta sentencia, va a reiterar la obligación de aplicar el control cv, pues favorece la complementariedad y la eficacia de la convención. Profundiza sobre los límites permitidos al artículo 13 de la CADH. En el 93 expresó que el control cv es una obligación propia de todo poder, órgano o autoridad del Estado Parte en la Convención los cuales deben, en el marco de sus respectivas competencias y de las regulaciones procesales correspondientes, controlar que los derechos humanos de las personas sometidas a su jurisdicción sean respetados y garantizados. Los jueces y órganos judiciales deben prevenir potenciales violaciones a derechos humanos reconocidos en la Convención Americana, o bien solucionarlas a nivel interno cuando ya hayan ocurrido, teniendo en cuenta las interpretaciones de la Corte Interamericana. Pues un adecuado control de convencionalidad a nivel interno fortalece la complementariedad del Sistema Interamericano y la eficacia de la $\mathrm{CADH}$ al garantizar que las autoridades nacionales actúen como garantes de los derechos humanos de fuente internacional. En el 94 manifestó que la decisión de la Corte Suprema de Chile constituyó un adecuado y oportuno control de convencionalidad de la sanción de amonestación privada impuesta al señor Urrutia Laubreaux en el 2005, en tanto reconoció, cesó y reparó parcialmente la violación al

\footnotetext{
${ }^{87}$ Corte IDH, Urrutia Labreaux con Chile, sentencia de 27 de agosto de 2020, párrafos 93 y 94.
} 
derecho a la libertad de expresión. Nuevamente, según lo estudiado, es una aplicación precisa, de los principios de justicia, equidad y prudencia. Es decir, y en especial tratándose de aplicación de sanciones disciplinarias a jueces, con mayor razón debemos aplicar la ética judicial.

Una reflexión final sobre lo cavilado. Es hora entonces, de dar un paso más y aceptar la interpretación internacional de los DDHH. La interpretación nacional aislada de las normas internacionales de DDHH es perjudicial, ya que permite a cada Estado establecer el significado y el contenido de los DDHH, lo que implica el riesgo de abuso y relativismo. Además, una interpretación puramente nacional niega la universalidad de los DDHH y reduce los tratados de DDHH y la Declaración Universal de los Derechos Humanos a textos retóricos. ${ }^{88}$

En suma, los jueces de la Corte IDH deben tener en consideración en su decisión final el código moral básico aludido. Al analizar las sentencias, es perfectamente distinguible la aplicación de la ética judicial.

\section{CONCLUSIONES}

Es claro que desde 1945 con la Carta ONU y luego con los demás instrumentos internacionales - que se han detallado- la comunidad jurídica internacional, ha colocado como pilar fundamental la dignidad humana, que constituye el fundamento de los DDHH. Siendo además esa dignidad el paradigma político y jurídico de la modernidad.

Los DDHH constituyen el nuevo derecho común del siglo XXI, que contienen valores, principios y normas compartidos por la mayoría de los individuos.

Es posible obtener racionalmente orientación moral sobre un determinado código moral, a partir de la Ética. Puesto que si la Ética, es una segunda reflexión sobre si debemos o no adherir a un específico código de conducta, ella nos orienta racionalmente. En este caso sobre el código moral básico apuntado.

${ }^{88}$ De Carvalho, André, "Control of Conventionality and the struggle to achieve a definitive interpretation of human rights: the Brazilian experience", Revista IIDH, 2017, Vol. 64, http://www. corteidh.or.cr/tablas/r36237.pdf, consultada: 27 de diciembre de 2018. 
La ética judicial que se ha estudiado, ha resultado relevante en la aplicación del instituto del control cv (fase externa). Ello, debido a que los jueces de la Corte IDH podrían haber naturalmente aplicado e interpretado el derecho de manera formal y dejar en los Estados nacionales su aplicación y práctica, pero sucede que, examinando los principios éticos del Código IEJ, lo que hizo la Corte IDH principalmente, es lo que señalan los principios de justicia, equidad y prudencia. Es decir, esos jueces hicieron uso de la ética judicial. En efecto, en cuanto deber ético, ellos cumplieron en grado de excelencia, con su deber jurídico, eligiendo racionalmente el código moral citado. De esta forma se alejaron de la mediocridad y optaron por la excelencia en su trabajo.

El control $c v$ constituye hoy, la mayor manifestación ética para la protección de los DDHH realizada por la Corte IDH en las dos primeras décadas del siglo XXI. Ello, pues ha resultado un cambio de tal magnitud, que ha significado la revisión del derecho y prácticas judiciales de los Estados Parte, sin precedente inmediato. Siendo el derecho no estático, sino dinámico.

Es decir, como se expresó en la introducción, este habitar del ser humano que constituye la Ética, ha venido realizándose de manera clara y precisa. Integrando nuestras prácticas jurisdiccionales en valores humanos a través del control $c v$.

Los miembros de la Corte IDH han tomado una decisión determinada, de manera sólida y fundamentada, dando razón de ello. Asimismo, al ser humano como homo sapiens, no le queda más remedio que avanzar hacia el homo ethicus para diseñar un mundo más habitable.

Por todo lo anterior, podemos sostener que la ética judicial ha desempeñado y desempeña actualmente un rol principal en la aplicación del control $c v$ (fase externa). Resultado de ello, la revisión de las prácticas judiciales de los Estados Parte de la CADH. Significando ello, además, una mayor comprensión y completitud del derecho. 


\section{BIBLIOGRAFÍA CITADA}

\section{a) Doctrina}

Aguilar, Gonzalo, "Derechos Fundamentales-Derechos Humanos. ¿Una distinción válida en el siglo XXI?", Boletín Mexicano de Derecho Comparado, 2010, $\mathrm{n}^{\circ}$ 127, pp. 15-71, https://revistas.juridicas.unam.mx/index.php/derechocomparado/article/view/4594, consultada: 6 de noviembre de 2020.

Aguilar, Gonzalo, "El control de convencionalidad: Análisis en Derecho Comparado", Revista Direito GV (Sao Paulo), 2013, Vol. 9, n 2, pp. 721-754.

Aguiló, Josep, "Dos concepciones de la ética judicial", Revista DOXA, 2009, $\mathrm{n}^{\circ} 32$, pp. 525-540, http://www.cervantesvirtual.com/obra/dos-concepciones-dela-etica-judicial/, consultada: 10 de octubre de 2018.

Alexy, Robert, Teoría de los derechos fundamentales. (Trad. de Carlos Bernal), Centro de Estudios Políticos y Constitucionales, Madrid, 2008, $2^{\mathrm{a}}$ edición.

AlveAr, Julio, "Algunas anotaciones sobre la enseñanza de la Ética jurídica", Actualidad Jurídica (Universidad del Desarrollo), 2002, año III, $\mathrm{N}^{\circ}$ 6, pp. 27-34.

Angulo, Geofredo, Teoría contemporánea de los Derechos Humanos. Elementos para una reconstrucción sistémica, Editorial Dykinson, S.L., Madrid, 2015.

Aranguren, José, Ética, Editorial Biblioteca Nueva, Madrid, 2009.

Aristóteles, Ética a Nicómaco, Ediciones Mestas, Madrid, 2003, 2a edición.

AtienZA, Manuel, "Ética Judicial", Jueces para la democracia (España), 2001, No 40 , pp. 17-18, https://dialnet.unirioja.es/servlet/articulo?codigo=174851, consultada: 3 de octubre de 2018.

Bachelard, Gastón, La poética del espacio, Fondo de Cultura Económica, Buenos Aires, 2000, $4^{\mathrm{a}}$ reimpr., $1^{\mathrm{a}}$ ed. argentina.

Benda, Ernesto, "Dignidad Humana y derechos de la personalidad", en Benda, E.; Mainofer, W.; Vogel, H.; Hesse, K.; Heyde, W. (coords.), Manual de Derecho Constitucional, Marcial Pons, Madrid, 2001, 2a edición, pp. 117-144.

Brandt, Richard, Teoría Ética, Alianza Editorial, Madrid, 1994.

Cianciardo, Juan; Zambrano, Pilar, “¿Para qué sirve el derecho si incorpora la moral?, Revista Chilena de Derecho, 2015, Vol. 42, № 2, pp. 615-648.

CONSEJO GENERAL DEL PODER JUdicial ESPAÑol, "Estatuto del Juez Iberoamericano", 2001, documento .pdf, http://www.poderjudicial. gob.hn/CUMBREJUDICIALIBEROAMERICANA/Documents/ estatutodeljueziberoamericano.pdf, consultada: 10 de noviembre de 2018.

Cortina, Adela; Martínez, Emilio, Ética, Akal, Madrid, 2001, $3^{\text {a }}$ edición.

CortinA, Adela, Ética aplicada y democracia radical, Tecnos, Madrid, 2012, $6^{\mathrm{a}}$ edición.

De Carvalho, André, "Control of Conventionality and the struggle to achieve a definitive interpretation of human rights: the Brazilian experience", Revista 
IIDH, 2017, Vol. 64, http://www.corteidh.or.cr/tablas/r36237.pdf, consultada: 27 de diciembre de 2018.

DíAz, Juan, "Ética Judicial”, en: SaldañA, J. (coord.), Ética Jurídica. Segundas Jornadas, UNAM, Instituto de Investigaciones Jurídicas, México D.F., 2015, pp. 185-196, https://biblio.juridicas.unam.mx/bjv/detalle-libro/3970-eticajuridica-segundas-jornadas, consultada: 25 de agosto de 2018.

EsCRIBAR, Ana, "La ética aplicada, sus condiciones de posibilidad y las exigencias a las que responde", Revista de Filosofía, 2004, Vol. 60, pp. 19-28, http://repositorio.uchile.cl/bitstream/handle/2250/131966/La-etica-aplicadasuscondiciones-de-posibilidad-y-exigencias-a-las-que-responde.pdf? sequence, consultada: 10 de noviembre de 2018.

Ferrater, José, Diccionario de Filosofía Abreviado, Editorial Sudamericana S.A., Buenos Aires, 2007, $28^{\mathrm{a}}$ edición.

García, Gonzalo, "Preguntas esenciales sobre el control de convencionalidad difuso aplicables a Chile", en: NogueIRA, H. (coord.), La protección de los Derechos Humanos y fundamentales de acuerdo a la Constitución y el Derecho Internacional de los Derechos Humanos, Librotecnia, Santiago de Chile, 2014, pp. 356-357.

García, Javier, "El Preámbulo contexto hermenéutico del Convenio: Un instrumento constitucional del orden público europeo", en: GARCía, J. y SANTOLAYA, P. (coords.), La Europa de los derechos. El Convenio Europeo de Derechos Humanos, Centro de Estudios Políticos y Constitucionales, Madrid, 2009, $2^{\text {a }}$ edición, pp. 25-53.

García, Sergio, Temas de Derecho, Universidad Autónoma del Estado de México, México, 2002.

GonzÁlez, Juan Carlos, Diccionario de Filosofía, Bilblioteca EDAF, Madrid, 2000 .

GonzÁlez, Nazario, Los Derechos Humanos en la Historia, Alfaomega, México, 2002.

GRANDE, Miguel, Ética de las profesiones jurídicas, Eds. Desclée De Brouwer, Bilbao, 2010, 2a edición, https://www.edesclee.com/img/cms/pdfs/9788433020406. pdf, consultada: 10 de noviembre de 2018.

Henríquez, Miriam y morales, Mariela, "Presentación", en: Henríquez, M.; Morales, M. (coords.), El Control de Convencionalidad: Un balance comparado a 10 años de Almonacid Arellano vs. Chile, DER Ediciones, Santiago de Chile, 2017, pp. 5-14.

InSTITUTO DE DERECHOS humanos BaRTOLOMÉ DE LAS CASAS, "Los Derechos Humanos en el contexto Ético, Jurídico y Político", Madrid, 2010, documento .pdf, http://www.tiempodelosderechos.es/docs/dic10/dhcontexto.pdf, consultada: 20 de octubre de 2018.

Lahoti, Shri RC, "Cánones de la ética judicial”, Nueva Delhi, 2005, 45 p., http://www.judicialethics.umontreal.ca/en/codes\%20enonces\%20deonto/docu 
ments/CODE_iNDE.pdf, consultada: 25 de diciembre de 2018 (Traducción propia).

Loewe, Daniel, Ética y Coronavirus, Fondo de Cultura Económica S.A., Santiago, 2020.

López, José, "Prólogo", en: Angulo, G., Teoría contemporánea de los Derechos Humanos. Elementos para una reconstrucción sistémica, Editorial Dykinson, Madrid, 2015, pp. 1-21.

MAC-GREgor, Eduardo, "El Control de Convencionalidad en la Jurisprudencia de la Corte Interamericana de Derechos Humanos (a una década de su creación: 2006-2016)", en: Henríquez, M.; Morales, M. (coords.), El Control de Convencionalidad: Un balance comparado a 10 años de Almonacid Arellano vs. Chile, DER Ediciones, Santiago de Chile, 2017, pp. 37-66.

MesA, Álvaro, "El control de convencionalidad: ¿un acto racional o irracional?, Estudios Constitucionales, 2018, No 1, pp. 129-166, https://scielo. conicyt.cl/pdf/estconst/v16n1/0718-5200-estconst-16-01-00129.pdf, consulta: 20 de octubre de 2018.

Nash, Claudio, Derecho Internacional de los Derechos Humanos en Chile. Recepción y aplicación en el ámbito interno, Universidad de Chile - Centro de Derechos Humanos, Santiago, 2012.

Nash, Claudio, "Control de Convencionalidad en Chile. Bases normativas, Jurisprudencia y críticas", en: Henríquez, M.; Morales, M. (coords.) El Control de Convencionalidad: Un balance comparado a 10 años de Almonacid Arellano vs. Chile, DER Ediciones, Santiago de Chile, 2017, pp. 403- 446.

NúÑEz, Constanza, El control de convencionalidad en la jurisprudencia de la Corte Interamericana de Derechos Humanos, ARA Editores, Buenos Aires, 2017.

Palacios, José, "Ética aplicada, interculturalidad y acción social", Revista del CISEN (Argentina), 2014, Vol. 2, n 1, pp. 63-83, http://ppct.caicyt.gov.ar/index. $\mathrm{php} / \mathrm{cisen} / \mathrm{search} /$ results, consultada: 1 de octubre de 2018.

Pérez, Antonio, Derechos Humanos, Estado de Derecho y Constitución, Tecnos, Madrid, 2010, 10 a edición.

Poder judicial de Chile, Código Iberoamericano de Ética Judicial, Poder Judicial República de Chile, Santiago, 2018.

Saldaña, Javier, Ética Judicial. Virtudes del Juzgador, Suprema Corte de Justicia de la Nación, México D.F., 2007, 124 p., https://sistemabibliotecario.scjn. gob.mx/sisbib/2018/000291845/000291845.pdf, consultada: 25 de noviembre de 2018.

Singer, Peter, Ética práctica, Cambridge University Press, Cambridge, 1995, $2^{\text {a }}$ edición.

Squella, Agustín, Introducción al Derecho, Editorial Jurídica de Chile, Santiago, 2001.

TruYol, Antonio, Los Derechos Humanos, Tecnos, Madrid, 1982, 3a edición.

Tugendhat, Ernst, Lecciones de Ética, Gedisa, Barcelona, 1997. 
Verbic, Francisco, "Control de Convencionalidad en el Sistema Interamericano de Protección de Derechos Humanos. Principales Características y Algunos Apuntes sobre su Aplicación en el Ordenamiento Jurídico Argentino", Ponencia, XXIII Jornadas Iberoamericanas de Derecho Procesal y I Conferencia Internacional sobre Procesos Colectivos, Buenos Aires, 2012: documento .pdf, en línea: http://www.academia.edu/3617712/Control_de_Convencionalidad_en_ el_Sistema_Interamericano_de_Protecci\%C3\%B3n_de_Derechos_Humanos. Principales_Caracter\%C3\%ADsticas_y_Algunos_Apuntes_sobre_su_Apl, consultada: 28 de octubre de 2018.

VIGO, Rodolfo, Ética y responsabilidad judicial, 2007, http://www2.scjn. gob.mx/red2/investigacionesjurisprudenciales/seminarios/3er-seminario-eticajudicial/etica-judicial-su-especificidad-y-responsabilidad.pdf, consultada: 26 de octubre de 2018.

Vio, Eduardo, "Jurisprudencia de la Corte Interamericana de Derechos Humanos: ¿del control de convencionalidad a la supranacionalidad?” en: STEINER, Christian (ed.) Anuario de Derecho Constitucional Latinoamericano 2015, Konrad Adenauer Stiftung, Bogotá, 2015, pp. 93-112.

Von bogdandy, Armín, "Prólogo", en: Henríquez, M.; Morales, M. (coords.), El Control de Convencionalidad: Un balance comparado a 10 años de Almonacid Arellano vs. Chile, DER Ediciones, Santiago de Chile, 2017, pp. 1-4.

\section{b) Normativa citada}

Carta de Constitución de Naciones Unidas, 1945.

Estatuto de la Corte Internacional de Justicia, 1945.

Carta de Constitución de la Organización de Estados Americanos, 1948.

Declaración Americana de los Derechos y Deberes del Hombre, 1948.

Declaración Universal de Derechos Humanos, 1948.

Convención Internacional Sobre Eliminación de todas las Formas de Discriminación Racial, 1965.

Pacto Internacional de Derechos Económicos, Sociales y Culturales, 1966.

Pacto Internacional de Derechos Civiles y Políticos, 1966.

Convención de Viena sobre el Derecho de los Tratados, 1969.

Convención Americana sobre Derechos Humanos, 1969.

Convención sobre la Eliminación de Todas las Formas de Discriminación contra la Mujer, 1979.

Convención Contra la Tortura y otros Tratos o Penas Crueles, Inhumanos o Degradantes, 1984.

Convención Interamericana para prevenir y sancionar la Tortura, 1985.

Convención sobre los Derechos del Niño, 1989.

Convención Interamericana para prevenir, sancionar y erradicar la violencia contra la mujer, 1995. 


\section{c) Jurisprudencia citada}

Corte Interamericana de Derechos Humanos, Opinión consultiva OC-2/82 (1982), 24 de septiembre de 1982. El efecto de las reservas sobre la entrada en vigencia de la Convención Americana sobre Derechos Humanos solicitada por Comisión Interamericana de Derechos Humanos, serie $\mathrm{A} \mathrm{N}^{\mathrm{o}} 02$.

Corte Interamericana de Derechos Humanos, 25 de noviembre de 2003, Myrna Mack Chang vs. Guatemala (2003), Fondo, reparaciones y costas. Serie C, $\mathrm{N}^{\mathrm{o}} 101$.

Corte Interamericana de Derechos Humanos, 26 de septiembre de 2006, Almonacid Arellano y otros vs. Chile (2006), Excepciones preliminares, fondo, reparaciones y costas. Serie C, No 154.

Corte Interamericana de Derechos Humanos, 20 de noviembre de 2007, Boyce y otros vs. Barbados (2007), Excepciones preliminares, fondo, reparaciones y costas. Serie C, No. 169.

Corte Interamericana de Derechos Humanos, 26 de noviembre de 2010, Cabrera García y Montiel Flores vs. México (2010), Excepción preliminar, fondo, reparaciones y costas. Serie $C, N^{\circ} 220$.

Corte Interamericana de Derechos Humanos, 24 de febrero de 2011, Gelman vs. Uruguay (2011), Fondo y reparaciones. Serie C, $\mathrm{N}^{\circ} 221$.

Corte Interamericana de Derechos Humanos, 4 de septiembre de 2012, Masacres de Río Negro vs. Guatemala (2012), Fondo y reparaciones. Serie C, N ${ }^{\circ}$ 250.

Corte Interamericana de Derechos Humanos, 27 de noviembre de 2013, $J$. vs. Perú (2013), Excepción preliminar, fondo, reparaciones y costas. Serie C, N ${ }^{\circ}$ 275.

Corte Interamericana de Derechos Humanos, 8 de febrero de 2018, San Miguel Sosa y otras vs. Venezuela (2018), Fondo, reparaciones y costas, Serie C, $\mathrm{N}^{\circ} 348$.

Corte Interamericana de Derechos Humanos, 27 de agosto de 2020, Urrutia Labreaux vs. Chile (2020), Excepciones Preliminares, Fondo, Reparaciones y Costas. Serie C, 409. 